DOI: $10.5216 /$ cab.v13i3.17527

\title{
GANHO DE PESO PRÉ E PÓS-DESMAME NO DESEMPENHO REPRODUTIVO DE NOVILHAS DE CORTE AOS QUATORZE MESES DE IDADE
}

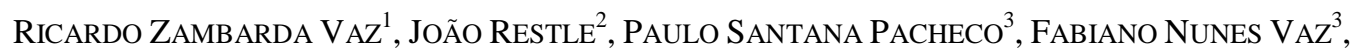 \\ LEONIR LUIZ PASCOAL ${ }^{3}$, MARCIA BITENCOURT VAZ
}

\author{
${ }^{1}$ Professor Doutor da Universidade Federal de Pelotas, Pelotas, RS, Brasil. - rzvaz@ terra.com.br \\ ${ }^{2}$ Professor Doutor visitante da Universidade Federal do Tocantins, Araguaína, TO, Brasil. \\ ${ }^{3}$ Professores Doutores da Universidade Federal de Santa Maria, Santa Maria, RS, Brasil. \\ ${ }^{4}$ Bolsista Universidade Regional Integrada no Campus de Santiago, Santiago, RS, Brasil.
}

Foram estudados o desenvolvimento e o desempenho reprodutivo de 66 novilhas mestiças Charolês, acasaladas aos quatorze meses de idade, classificadas em quatro grupos, conforme o ganho de peso médio diário (GMD) pré e pós-desmame: $\mathrm{AA}=$ novilhas com GMD superior a $0,54 \mathrm{~kg}$ e $0,73 \mathrm{~kg}$, respectivamente; $\mathrm{AB}=$ novilhas com GMD superior a $0,54 \mathrm{~kg}$ e inferior $0,73 \mathrm{~kg}$, respectivamente; $\mathrm{BA}=$ novilhas com $\mathrm{GMD}$ inferior a $0,54 \mathrm{~kg}$ e superior a $0,73 \mathrm{~kg}$, respectivamente; $\mathrm{BB}=$ novilhas com GMD inferior a $0,54 \mathrm{~kg}$ e $0,73 \mathrm{~kg}$, respectivamente. $\mathrm{O}$ peso no início e no final do período de acasalamento, bem como o desempenho reprodutivo das novilhas foi influenciado pelo ganho de peso das novilhas nas fases pré e pós-desmame. O grupo AA mostrou melhor desenvolvimento sobre os demais, não havendo diferença entre os grupos $\mathrm{AB}$ e BA. O grupo AA foi superior aos demais no desempenho reprodutivo com exceção do grupo AB. As novilhas cíclicas apresentaram desenvolvimento superior durante a recria e o período de acasalamento do que as novilhas acíclicas. O desempenho reprodutivo das novilhas correlacionou-se positivamente com peso e condição corporal no início e no final do período reprodutivo. Maiores ganhos de peso nas fases pré e pós-desmame melhoram o desempenho reprodutivo de novilhas de corte.

PALAVRAS-CHAVE: Charolês; condição corporal; estro; peso ao acasalamento; prenhez.

\section{PRE AND POSTWEANING WEIGHT GAIN ON REPRODUCTIVE PERFORMANCE OF BEEF HEIFERS AT FOURTEEN MONTHS OF AGE}

\section{ABSTRACT}

The objective of this experiment was to study the development and reproductive performance of sixty-six Charolais crossbred beef heifers bred at fourteen months of age, classified in four groups according to pre and postweaning average daily weight gain (ADG): $\mathrm{AA}=$ heifers that showed $\mathrm{ADG}>.54 \mathrm{~kg}$ and $.73 \mathrm{~kg}$, respectively; $\mathrm{AB}=$ heifers that showed $\mathrm{ADG}>.54 \mathrm{~kg}$ and $<.73 \mathrm{~kg}$, respectively; $\mathrm{BA}=$ heifers that showed $\mathrm{ADG}<$ $.54 \mathrm{~kg}$ and $>.73 \mathrm{~kg}$, respectively; $\mathrm{BB}=$ heifers that showed $\mathrm{ADG}<.54 \mathrm{~kg}$ and $<.73 \mathrm{~kg}$, respectively. Weight at the beginning and end of the breeding period, and the reproductive performance were influenced by ADG of the heifers during pre and postweaning phase. AA heifers showed better development in relation to the other groups, without difference between $\mathrm{AB}$ and $\mathrm{BA}$. The AA group was superior to the others except for the reproductive performance of the group $\mathrm{AB}$. Heifers that became cyclical showed higher development during the growing phase and mating period than acyclic heifers. Reproductive performance of heifers was positively correlated with weight and body condition at beginning and end of the mating period. Greater weight during pre and post-weaning improve the reproductive performance of beef heifers.

KEYWORDS: body condition; Charolais; estrus; pregnancy; weight at mating. 


\section{INTRODUÇÃO}

A redução da idade ao primeiro acasalamento melhora a eficiência reprodutiva do rebanho, em função da maior pressão de seleção, escolha precoce das melhores matrizes e diminuição do intervalo entre gerações, propiciando um retorno mais rápido do investimento realizado no rebanho.

Ao intensificar os sistemas de produção reduzindo a idade de acasalamento das novilhas e melhorando a eficiência reprodutiva dos rebanhos de cria, o nível nutricional é fundamental para a manifestação da puberdade nas fêmeas. Segundo RESTLE et al. (1999), em sistemas produtivos mais intensificados, a importância do início da atividade reprodutiva nas fêmeas bovinas influencia no desempenho do rebanho de cria, pois é necessário que a primeira concepção seja em idade apropriada para atingir os objetivos propostos.

A idade de puberdade de fêmeas bovinas é influenciada pela interação do genótipo com o ambiente. Dentre aos fatores ambientais, destaca-se o nível nutricional aos quais as fêmeas são submetidas desde o nascimento até o acasalamento, pois a manifestação da puberdade ocorre quando a fêmea alcança um determinado desenvolvimento e isso é consequência da velocidade do ganho de peso (RESTLE et al., 1999).

À medida que se intensificam os sistemas de produção reduzindo-se as idades de abate e de acasalamento, o desempenho animal torna-se fundamental para alcançar os objetivos propostos pelos sistemas produtivos. Com a diminuição da idade de acasalamento, o desenvolvimento prédesmame torna-se mais importante por representar, percentualmente, maior período desde o nascimento até o acasalamento (PATTERSON et al., 1992), embora o desenvolvimento pós-desmame correlacione-se positivamente com o desempenho reprodutivo de novilhas de corte (ROCHA \&
LOBATO, 2002).

O objetivo deste trabalho foi estudar diferentes ganhos de pesos pré e pós-desmame e os seus reflexos no desenvolvimento e desempenho reprodutivo de novilhas expostas a reprodução aos quatorze meses.

\section{MATERIAL E MÉTODOS}

O experimento foi desenvolvido nas dependências do Departamento de Zootecnia da Universidade Federal de Santa Maria, localizada na região fisiográfica denominada de Depressão Central do Estado do Rio Grande do Sul. A altitude é de 95 $\mathrm{m}$, latitude $29^{\circ} 43^{\prime}$ sul e longitude de $53^{\circ} 42^{\prime}$ oeste. $\mathrm{O}$ clima da região é Cfa (subtropical úmido), conforme a classificação de Köppen (MORENO, 1961).

Foram utilizadas 66 bezerras mestiças Charolês com Nelore, com predominância de sangue Charolês, de um só rebanho experimental, mantidas sempre sob as mesmas condições de manejo, nascidas nos meses de setembro, outubro e novembro. $\mathrm{O}$ experimento foi dividido em duas fases, pré e pós-desmame, e foram comparados quatro grupos de animais: Alto-Alto = animais com ganho de peso corporal médio diário superior a 0,54 $\mathrm{kg}$ (variação entre 0,562 e $0,895 \mathrm{~kg}$ ) e $0,73 \mathrm{~kg}$ (variação entre 0,754 e $1,155 \mathrm{~kg}$ ), respectivamente; Alto-Baixo = animais com ganho de peso corporal médio diário superior a $0,54 \mathrm{~kg}$ e inferior 0,73 (variação entre 0,422 e $0,729 \quad \mathrm{~kg}$ ) $\mathrm{kg}$, respectivamente; Baixo-Alto $=$ animais $\mathrm{com}$ ganho de peso corporal médio diário inferior a $0,54 \mathrm{~kg}$ (variação entre 0,215 e 0,533 ) e superior a $0,73 \mathrm{~kg}$, respectivamente; Baixo-Baixo = animais com ganho de peso corporal médio diário inferior a $0,54 \mathrm{~kg}$ e $0,73 \mathrm{~kg}$, respectivamente. As composições dos grupos estudados podem ser observadas na Tabela 1.

Tabela 1 - Classificação dos grupos conforme os ganhos de peso nas diferentes fases

\begin{tabular}{lcccc}
\hline Ganhos de pesos & Alto-Alto & Alto- Baixo & Baixo-Alto & $\begin{array}{c}\text { Baixo- } \\
\text { Baixo }\end{array}$ \\
\hline Do nascimento ao desmame, $\mathrm{kg}$ & $>0,54$ & $>0,54$ & $<0,54$ & $<0,54$ \\
Do desmame ao início do período reprodutivo, $\mathrm{kg}$ & $>0,73$ & $<0,73$ & $>0,73$ & $<0,73$ \\
Número de animais/ grupo & 14 & 17 & 20 & 15 \\
\hline
\end{tabular}


As novilhas foram sempre submetidas ao mesmo manejo nutricional e sanitário, sendo as fêmeas mães das bezerras oriundas e contemporâneas do mesmo rebanho experimental. A formação dos grupos estudados foi realizada através dos ganhos de pesos corporais individuais das novilhas nos dois períodos de avaliação, tendo como base da divisão dos mesmos a média geral dos ganhos de peso corporal nos períodos. Os ganhos de peso no período pré-desmame oscilaram de 0,215 a 0,533 e de 0,562 a $0,895 \mathrm{~kg} / \mathrm{dia}$, respectivamente, para níveis baixo e alto. Já no período pós-desmame, os ganhos de peso corporal oscilaram de 0,422 a 0,719 e de 0,754 a $1,155 \mathrm{~kg} /$ dia, respectivamente, para níveis baixo e alto.

As fêmeas foram mantidas em pastagem nativa com suas mães até a época do desmame com carga animal de uma vaca com cria por hectare. $\mathrm{O}$ desmame foi realizado quando as bezerras alcançaram a idade média de 210 dias. Dos sete aos quatorze meses permaneceram em pastagem cultivada de inverno composta de Triticale (Tritico secale) e Azevém (Lolium multiflorum), com uma lotação média de 5,7 fêmeas/ha ou $1200 \mathrm{~kg}$ de peso vivo/ha.

O período reprodutivo teve duração de 90 dias (dos quatorze aos dezesseis meses de idade), e as fêmeas foram mantidas em campo nativo previamente roçado e diferido com lotação média de 3,0 novilhas/ha ou $810 \mathrm{~kg}$ de peso/ha. Conforme a manifestação de estro, as novilhas foram inseminadas. Os estros foram determinados sem a utilização de rufiões, com duas observações diárias para sua identificação, sendo uma pela manhã (6:00 horas) e outra à tarde (18:00 horas). As novilhas que manifestavam estro pela manhã eram inseminadas à tarde e as que manifestavam estro à tarde eram inseminadas na manhã do dia seguinte, logo após o período de observação. Utilizou-se sêmen da raça Aberdeen Angus (variedade Red), oriundo de um único touro com Dep negativa para peso ao nascimento, procurando-se evitar problemas de distocia. O diagnóstico de prenhez foi realizado 60 dias após o término do período reprodutivo, por meio de palpação retal.

Por ocasião do momento da inseminação, as novilhas foram pesadas e, pela diferença entre a data da inseminação em relação à data de nascimento, foi determinada a idade no momento da inseminação. As novilhas foram pesadas a cada 28 dias desde o nascimento até o final do período de acasalamento, bem como por ocasião do desmame e do início do período reprodutivo. Em relação ao peso ao final do período reprodutivo, foi determinado o escore de condição corporal utilizando-se escores de 1 a 5, em que: 1- muito magra; 2- magra; 3- média; 4- gorda e
5- muito gorda (LOWMAN et al., 1973).

No desempenho reprodutivo, foram avaliadas as taxas de manifestação de estros, taxa de prenhez e de distribuição dos estros dentro do período reprodutivo, além de peso e idade na ocasião da inseminação. A distribuição de estros foi determinada por meio da divisão do período reprodutivo em três fases: inicial, mediana e final (com 30 dias cada fase), em que se determinou o percentual de fêmeas cíclicas dentro dos períodos de acordo com os desempenhos animais prévios ao período reprodutivo.

O número de serviços para a concepção foi determinado através do número de inseminações realizadas nas novilhas durante $\mathrm{o}$ período reprodutivo, sendo que para as novilhas que manifestaram somente um estro sem a chance de manifestar outro pelo término do período reprodutivo e não ficaram prenhes foi considerado mais um serviço para a sua concepção.

Durante o período experimental, os animais receberam suplementação mineral adequada à categoria e à época do ano em cochos distribuídos no potreiro de campo nativo. As vacinações seguiram o calendário da Secretaria da Agricultura - RS, e o controle de endo e ectoparasitas foi realizado com produtos específicos, de acordo com o grau de infestação, sendo os últimos determinados visualmente.

$\mathrm{O}$ delineamento experimental foi inteiramente casualizado, num fatorial $2 \times 2$ (dois ganhos de pesos pré e dois ganhos de pesos pósdesmame) com número diferente de repetições dentro dos tratamentos, sendo os dados submetidos à análise de variância, seguindo o modelo abaixo:

$$
\mathrm{Y}_{\mathrm{ijk}}=\mu+\mathrm{TRAT}_{\mathrm{i}}+\mathrm{IN}_{\mathrm{j}}+\mathrm{IV}_{\mathrm{k}}+(\mathrm{IV} * \mathrm{IV})_{\mathrm{k}}+\mathrm{E}_{\mathrm{ijk}}
$$

Em que: $Y_{\mathrm{ijk} l}=$ variáveis dependentes; $\mu$ médias observadas; TRAT $_{i}=$ efeito dos ganhos de peso corporal nos períodos pré e pós-desmame de ordem $i$, sendo $i=1$ (ganhos de pesos corporais baixos no pré e pós-desmame); 2 (ganhos de peso corporal baixos no pré e altos no pós-desmame); 3 (ganhos de peso corporal altos no pré e baixos no pós-desmame) e 4 (ganhos de peso corporal altos no pré e pós-desmame); $\mathrm{IN}_{\mathrm{j}}=$ covariável idade do animal no início do experimento de ordem $\mathrm{j} ; \mathrm{IV}_{\mathrm{k}}=$ covariável idade da vaca de ordem $\mathrm{k} ; \mathrm{E}_{\mathrm{ijk}}=$ erro aleatório assumindo distribuição normal com média igual a zero e variânca $\sigma^{2}$. Quando o $F$ foi significativo $(\mathrm{P}<0,05)$, realizou-se o teste Tukey para comparação das médias (5\%).

Para as análises de variância comparando-se novilhas cíclicas ou acíclicas, utilizou-se o seguinte modelo: $\mathrm{Y}_{\mathrm{ijk} \mathrm{l}}=\mu+\mathrm{CIO}_{\mathrm{i}}+\mathrm{IN}_{\mathrm{j}}+\mathrm{IV}_{\mathrm{k}}+\mathrm{E}_{\mathrm{ijk}}$, em que: 
$\mathrm{Y}_{\mathrm{ijk}}=$ variáveis dependentes; $\mu$ - médias observadas; $\mathrm{CIO}_{\mathrm{i}}=$ efeito da manifestação de cios de ordem i, sendo $\mathrm{i}=1$ (cíclicas); 2 (acíclicas); $\mathrm{IN}_{\mathrm{j}}=$ covariável idade do animal no início do experimento de ordem $\mathrm{j} ; \mathrm{IV}_{\mathrm{k}}=$ covariável idade da vaca de ordem $\mathrm{k} ; \mathrm{E}_{\mathrm{ijk}}=$ erro aleatório assumindo distribuição normal com média igual a zero e variânca $\sigma^{2}$.

Ao início do período reprodutivo, as novilhas foram classificadas quando ao seu peso corporal em quatro categorias: novilhas com peso corporal de $316 \mathrm{~kg}$ ou mais, novilhas com peso corporal entre 280 e $315 \mathrm{~kg}$, novilhas com peso corporal entre 245 e $279 \mathrm{~kg}$ e novilhas com peso corporal inferior a $244 \mathrm{~kg}$ e a influência dos mesmos na manifestação de cios e percentagem de prenhez, sendo as faixas avaliadas pelo teste do Qui-quadrado a $5 \%$.

As comparações relacionadas aos efeitos dos ganhos de peso corporal antes e após os sete meses foram realizadas por intermédio de análises de contrastes, realizando-se as seguintes comparações: 1) alto-alto + alto-baixo contra baixo-alto + baixobaixo e 2) alto-alto + baixo-alto contra alto-baixo + baixo-baixo, sendo que o contraste 1 permite uma estimativa do efeito do ganho de peso antes de sete meses e o contraste 2 , uma estimativa do efeito do ganho de peso após os sete meses sobre as características dependentes estudadas.

\section{RESULTADOS E DISCUSSÃO}

$\mathrm{Na}$ comparação individual dos grupos, verifica-se a superioridade $(\mathrm{P}<0,0001)$ dos animais alto-alto e alto-baixo até a idade do desmame, em média aos 210 dias, em que os mesmos foram mais pesados quando comparados aos animais baixo-alto e baixo-baixo (Tabela 2).

Bezerras com maiores ganhos durante o período pré-desmame foram em média $46,5 \mathrm{~kg}$ mais pesadas que bezerras com menores ganhos de peso, correspondendo essa diferença em peso corporal a $38 \%$ de superioridade das novilhas mantidas com maior ganho de peso corporal. Esse fato é fundamental para resultados satisfatórios de prenhez a idades reduzidas, sendo o desenvolvimento da novilha determinante no seu desempenho reprodutivo (ROVIRA, 1996).

Após o desmame das bezerras, a análise estatística, na comparação individual entre os quatro grupos, mostrou efeito do ganho de peso, antes e após o desmame aos sete meses de idade, no peso ao início do período reprodutivo aos 14 meses, mantendo-se essa superioridade favorável a animais com maiores ganhos de peso corporal até o final do acasalamento.

Animais com melhores desempenhos no período pré e pós-desmame (alto-alto) foram 14,6, 21,1 e $31,0 \%$ superiores em peso corporal ao início do período de acasalamento, quando comparados com animais alto-baixo, baixo-alto e baixo-baixo, respectivamente. Maiores pesos corporais de novilhas ao início do período reprodutivo são influenciados pelo peso ao desmame e pelo nível alimentar no período pós-desmame com correlações positivas no desempenho reprodutivo de novilhas de corte (WILTBANK et al., 1985; PILAU \& LOBATO, 2006).

Tabela 2 - Médias e erros padrão para as características de desenvolvimento de novilhas de acordo com os ganhos de peso nos períodos pré e pós-desmame

\begin{tabular}{|c|c|c|c|c|c|c|c|}
\hline \multirow{3}{*}{$\begin{array}{l}\text { Período } \\
\text { Pré-desmame } \\
\text { Pós-desmame }\end{array}$} & \multicolumn{4}{|c|}{ Ganho de peso } & \multicolumn{2}{|c|}{ Contrastes } & \multirow{3}{*}{$\begin{array}{l}\text { Valor } \\
\text { de P }\end{array}$} \\
\hline & Alto & Alto & Baixo & Baixo & & & \\
\hline & Alto & Baixo & Alto & Baixo & Pré & Pós & \\
\hline \multicolumn{8}{|l|}{ Pesos e GMD, kg } \\
\hline Nascimento & $34 \pm 1,4^{\mathrm{a}}$ & $32 \pm 1,2^{\mathrm{ab}}$ & $31 \pm 1,1^{\mathrm{b}}$ & $31 \pm 1,5^{\mathrm{b}}$ & NS & NS & 0,0037 \\
\hline Desmame & $163 \pm 5,1^{\mathrm{a}}$ & $175 \pm 4,4^{\mathrm{a}}$ & $116 \pm 4,0^{\mathrm{b}}$ & $129 \pm 5,5^{b}$ & $* *$ & NS & 0,0001 \\
\hline Início acasalamento & $321 \pm 6,8^{\mathrm{a}}$ & $280 \pm 6,0^{\mathrm{b}}$ & $265 \pm 5,3^{\mathrm{bc}}$ & $245 \pm 7,4^{\mathrm{c}}$ & $* *$ & $* *$ & 0,0001 \\
\hline Final acasalamento & $365 \pm 9,4^{\mathrm{a}}$ & $329 \pm 8,2^{\mathrm{b}}$ & $320 \pm 7,4^{\mathrm{bc}}$ & $290 \pm 10,1^{\mathrm{c}}$ & $* *$ & $* *$ & 0,0001 \\
\hline GMD acasalamento & $0,487 \pm 0,07$ & $0,538 \pm 0,06$ & $0,600 \pm 0,06$ & $0,500 \pm 0,08$ & NS & NS & 0,5726 \\
\hline CC acasalamento \# & $3,47 \pm 0,07$ & $3,32 \pm 0,08$ & $3,33 \pm 0,07$ & $3,28 \pm 0,09$ & $*$ & NS & 0,3746 \\
\hline
\end{tabular}

Os pesos de 321, 280, 265 e $245 \mathrm{~kg}$ para alto-alto, alto-baixo, baixo-alto e baixo-baixo, respectivamente, significam $71,3,62,2,58,9$ e $54,4 \%$ do peso adulto do rebanho em estudo, no qual as 
vacas com $450 \mathrm{~kg}$ e com estado corporal acima de 3 pesam em média $450 \mathrm{~kg}$. Segundo o NRC (1996), novilhas Bos taurus devem ter no mínimo $60 \%$ do seu peso adulto para alcançar a puberdade e conceber.

No presente estudo, somente os grupos altoalto e alto-baixo possuíam no início do período reprodutivo pesos corporais aceitáveis para acasalamento aos 14 meses de idade. Esse fato reflete a necessidade de adequado desenvolvimento das novilhas para desempenhos reprodutivos compatíveis com uma pecuária de corte mais rentável.

A correlação entre peso ao início do acasalamento e a manifestação de estros e a percentagem de prenhez apresentou coeficientes de 0,48 e $0,37 \quad(\mathrm{P}<0,0001)$ respectivamente, demonstrando a importância do peso mais elevado ao início do acasalamento para melhores desempenhos reprodutivos, sendo o mesmo reflexo do desenvolvimento anterior das fêmeas, tanto no período pré como pós-desmame. Diversos autores observaram que o desenvolvimento pré-desmame tem influência no desempenho reprodutivo (PATTERSON et al., 1992), assim como na taxa de crescimento na fase pós-desmame (WILTBANK et al., 1985).

Novilhas com maiores ganhos de peso no período pré-desmame apresentaram maior taxa de manifestação de estros em relação aos demais níveis (Tabela 3; $\mathrm{P}>0,05)$. Ocorreu um incremento de $66,7 \%$ na taxa de manifestação de estros quando comparamos os tratamentos alto-alto com baixo-alto e baixo-baixo.

Em sistemas produtivos, ao se trabalhar com condições restritas de alimentação, deve-se melhorar o nível de nutrição para se obter bom desempenho reprodutivo de novilhas submetidas à reprodução em idades superjovens, ou ainda trabalhar com diferentes sistemas alimentares priorizando animais de menores pesos e desenvolvimento (SEMMELMANN et al., 2001).

Tabela 3 - Desempenho reprodutivo de novilhas de acordo com os ganhos de pesos nos períodos pré e pósdesmame

\begin{tabular}{lccccc}
\hline Período & \multicolumn{5}{c}{ Ganho de peso } \\
\cline { 1 - 4 } Pré-desmame & Alto & Alto & Baixo & Baixo & \multirow{2}{*}{ Valor de P } \\
Pós-desmame & Alto & Baixo & Alto & Baixo & \\
\hline Taxa manifestação estros, \% & $100,00^{\mathrm{A}}$ & $88,24^{\mathrm{A}}$ & $60,00^{\mathrm{B}}$ & $60,00^{\mathrm{B}}$ & 0,0022 \\
Taxa de prenhez, \% & $85,71^{\mathrm{A}}$ & $88,24^{\mathrm{A}}$ & $55,00^{\mathrm{B}}$ & $53,33^{\mathrm{B}}$ & 0,0229 \\
Peso a inseminação, kg & $323 \pm 9,2^{\mathrm{a}}$ & $304 \pm 8,2^{\mathrm{ab}}$ & $311 \pm 10,2^{\mathrm{ab}}$ & $276 \pm 13,5^{\mathrm{b}}$ & 0,0800 \\
Idade a inseminação, dias & $441 \pm 6,8^{\mathrm{a}}$ & $460 \pm 6,0^{\mathrm{ab}}$ & $472 \pm 7,5^{\mathrm{bc}}$ & $471 \pm 10,0^{\mathrm{bc}}$ & 0,0268 \\
\hline
\end{tabular}

\# A,B na mesma linha diferem pelo teste do Qui-quadrado (5\%).

${ }^{* a, b, c} \mathrm{Na}$ mesma linha seguidas por letras minúsculas diferentes diferem entre si $(\mathrm{P}<0,05)$ pelo teste Tukey.

A manifestação de estro (Tabela 3) refletiu os ganhos de peso corporal pré e pós-desmame e o escore de condição corporal ao final do período reprodutivo que as fêmeas apresentaram (Tabela 2). As percentagens de estros e de prenhez se correlacionaram de maneira positiva com os ganhos de peso e a condição corporal com coeficientes de 0,38 e $0,31 \quad(\mathrm{P}<0,0001)$, respectivamente. Esses resultados confirmam as observações anteriores de RESTLE et al. (1999), em que os autores verificaram ser a reprodução em fêmeas bovinas de corte altamente correlacionada com o ganho de peso e a condição corporal dos animais.

Embora o consumo dos animais não tenha sido avaliado, provavelmente, animais mantidos em condições de baixo ganho de peso não conseguiram suprir suas exigências nutricionais, prejudicando a reprodução em detrimento da manutenção e do crescimento animal. Baixos níveis alimentares são determinantes nas concentrações de hormônios relacionados à manifestação da puberdade e na manifestação de cios férteis, com diminuição dos níveis sanguíneos de GnRH, FSH e LH, determinantes de cios pobres, pouco crescimento folicular e menor período de dominância do folículo (KINDER et al., 1994).

Os pesos por ocasião da inseminação foram bastante similares nos três grupos em que as novilhas tiveram ganhos de peso corporal altos nos períodos pré, pós-desmame ou em ambos (Tabela 3). Esse fato demonstra a importância da qualidade da alimentação no desenvolvimento da novilha e sua 
relação com seu desempenho reprodutivo subsequente, pois seu desenvolvimento após a concepção até o parto é prejudicado pelo aumento das suas exigências nutricionais. Durante a gestação de novilhas, as demandas nutricionais de proteína, energia e minerais como cálcio e fósforo aumentam em 43, 55 e 66\%, respectivamente, acentuando-se no terço final de gestação (VALLE et al., 1998). Em situações de pastagens naturais, a qualidade das mesmas não permite o aporte ideal de nutrientes necessário para que a novilha atenda suas exigências nutricionais, tendo que recorrer a suas reservas corporais para atender as exigências de manutenção, crescimento e gestação.

Para manifestar a puberdade, é fundamental que a fêmea atinja um determinado grau de desenvolvimento e que a idade à puberdade seja, principalmente, uma consequência da velocidade de ganho de peso que, por sua vez, está condicionado ao meio ambiente, especialmente ao nível alimentar imposto. RESTLE et al. (1999) observaram que, em fêmeas da raça Charolês, a idade média à puberdade foi aos 626 dias, contra 391 dias obtidos por GREGORY et al. (1991) em ambiente mais favorável, sendo os pesos à puberdade similares. Dessa forma, a manifestação da puberdade se condiciona a uma inter-relação entre o peso corporal e a idade da novilha.

No presente estudo, verificou-se que os maiores ganhos de peso corporal no período prédesmame resultaram em melhor desempenho reprodutivo quando comparados com os tratamentos com maiores ganhos de peso no período pósdesmame. Isso se deve, em parte, ao fato de o período pré-desmame ser percentualmente maior do que o período pós-desmame, com valores de 53,8 e $46,2 \%$, respectivamente, ao se trabalhar com idade de acasalamento de 14 meses. Esse menor período da fase pós-desmame, embora com maiores ganhos de pesos corporais, proporcionados pela melhor alimentação, não foram suficientes para que novilhas compensassem o menor ganho de peso corporal no período pré-desmame. À medida que se intensifica o sistema produtivo e se acasalam novilhas com idades mais jovens, o período pré-desmame aumenta sua influência no desenvolvimento e consequente desempenho reprodutivo de novilhas de corte (RESTLE et al., 1999).

A idade com que as fêmeas manifestaram o primeiro estro dentro do período reprodutivo foi influenciada pelos ganhos de peso corporal das novilhas (Tabela 3). VAZ et al. (2012) não encontraram diferença na idade à puberdade em novilhas Charolês, Nelore e suas cruzas submetidas a diferentes níveis de suplementação durante o período reprodutivo aos 14 meses de idade.

ROCHA \& LOBATO (2002) mostraram que o desenvolvimento expresso em ganho de peso corporal das novilhas é de extrema importância no aparecimento do primeiro estro, estando inversamente relacionado com a idade de puberdade, concluindo ser a idade de puberdade correlacionada ao melhor o nível nutricional.

A correlação entre a idade e o peso, por ocasião da inseminação, independentemente dos ganhos de peso pré e pós-desmame, mostrou um coeficiente de $0,60 \quad(\mathrm{P}<0,0001)$, indicando que novilhas mais tardias dentro do período de reprodução também foram mais pesadas na inseminação. No entanto, entre os tratamentos, a melhor condição alimentar promoveu a inseminação dos animais com peso mais elevado e com idades menores. VAZ et al. (2010) salientam a importância da seleção dos animais com frames adaptados aos sistemas produtivos nos quais são criados. Animais com maior peso na concepção e consequente peso adulto são mais tardios além de aumentar as exigências de manutenção do rebanho de cria (WILLIAMS \& JENKINS, 1998), afetando os índices reprodutivos (VAZ et al., 2010).

Ao se trabalhar com entoure precoce de novilhas, é importante que essas fiquem prenhes no início do primeiro período reprodutivo, pois, após o parto, além dos requerimentos de manutenção, lactação e subsequente reprodução, como ocorre com vacas adultas, as novilhas ainda estão em crescimento. Quanto mais cedo a novilha entrar em estro e ficar prenhe, maior o intervalo entre o parto e o período de reprodução subsequente.

No tratamento alto-alto, no qual os animais tiveram melhores desempenhos em ganhos de peso corporal, a maior concentração de estro das novilhas se deu no primeiro terço do período reprodutivo $57,14 \%$, sendo esse superior em $61,87,571,40$ e $71,43 \%$ dos tratamentos alto-baixo, baixo-alto e baixo-baixo, respectivamente (Tabela 4).

VAZ et al. (2010), ao trabalharem com diferentes idades de desmame das novilhas, não observaram diferença entre as mesmas. Contudo, as maiores concentrações de estros nos períodos iniciais e intermediários do primeiro acasalamento, repetiram-se no segundo período reprodutivo, concordando com OSORO (1986), demonstrando que as novilhas que concebem no início do período reprodutivo e, consequentemente, parem no início da parição, são as que apresentam maior taxa de prenhez quando primíparas. Maior concentração de partos no início da temporada de parição possibilita maior intervalo entre o parto e o fim do segundo período reprodutivo. 
Tabela 4 - Distribuição de cios e número de serviços à concepção no primeiro período reprodutivo de novilhas com diferentes ganhos de peso nos períodos pré e pós-desmame

\begin{tabular}{|c|c|c|c|c|}
\hline \multirow{2}{*}{$\begin{array}{l}\text { Ganhos de pesos pré e } \\
\text { pós-desmame }\end{array}$} & \multicolumn{3}{|c|}{ Período de concepção, (\%) } & \multirow{2}{*}{$\begin{array}{l}\text { Número } \\
\text { Serviços }\end{array}$} \\
\hline & Inicial & Intermediário & Final & \\
\hline Alto-Alto & $57,14(8 / 14)^{\mathrm{a}}$ & $35,71(5 / 14)^{b}$ & $7,14(1 / 14)^{\mathrm{c}}$ & 2,0 \\
\hline Alto-Baixo & $35,30(6 / 17)^{\mathrm{a}}$ & $41,17(7 / 17)^{\mathrm{a}}$ & $23,52(4 / 17)^{\mathrm{b}}$ & 2,0 \\
\hline Baixo-Alto & $10,0(2 / 20)^{c}$ & $60,0(12 / 20)^{\mathrm{a}}$ & $30,0(6 / 20)^{\mathrm{b}}$ & 2,6 \\
\hline Baixo-baixo & $33,33(5 / 15)^{\mathrm{a}}$ & $40,00(6 / 15)^{\mathrm{a}}$ & $26,67(4 / 15)^{\mathrm{a}}$ & 2,8 \\
\hline Média & $31,82(21 / 66)^{\mathrm{b}}$ & $45,45(30 / 66)^{\mathrm{a}}$ & $22,72(15 / 66)^{\mathrm{c}}$ & \\
\hline
\end{tabular}

a,b,c na mesma linha diferem entre si pelo teste do qui-quadrado $(\mathrm{P}<0,05)$

ROCHA \& LOBATO (2002) concluíram que o peso ao desmame da bezerra é um bom indicador a ser usado junto com estratégias de nutrição para que um maior número de novilhas consiga conceber no início da reprodução e na temporada de monta subsequente e, mesmo lactando, favorecer a obtenção de maior taxa de prenhez.

A idade da puberdade das novilhas não foi avaliada, mas sim o número de serviços necessários para a concepção das novilhas. Dessa forma, não se sabe se o estro manifestado nos primeiros 21-24 dias do período reprodutivo foi realmente o primeiro estro das novilhas. O número de serviços necessários para a concepção foi crescente com menos serviços para animais mantidos nos sistemas com ganhos de peso alto-alto e alto-baixo, quando comparados com animais mantidos nos regimes alimentares baixo-alto e baixo-baixo, com valores de 2,0 e 2,7 serviços, respectivamente.

Os maiores ganhos de peso das novilhas proporcionaram menores números de serviços para concepção. Esse fato demonstra a necessidade de um melhor nível nutricional para o desencadeamento da puberdade precoce em novilhas, uma vez que a fertilidade dos estros em novilhas aumenta com o passar dos mesmos e novilhas acasaladas no terceiro ciclo estral apresentam melhor desempenho reprodutivo quando comparadas com novilhas acasaladas durante os ciclos iniciais da puberdade (BYERLEY et al., 1987). Dessa forma, nos sistemas produtivos, é aconselhável que as novilhas de reposição alcancem a puberdade cerca de 60 dias antes da estação de monta para terem condições de conceber no início do primeiro período reprodutivo e além de maior tempo de recuperação do parto até o período reprodutivo subsequente.

O ganho de peso anterior ao período reprodutivo é fundamental no desempenho reprodutivo de novilhas, pois corresponde a um aporte de nutrientes adequado que desencadeia a secreção e liberação de hormônios ligados à reprodução (SCHILLO, 1992). À medida que a novilha recebe maior aporte de proteína e principalmente energia, os ciclos pulsáteis de $\mathrm{LH}$ manifestam-se de forma mais intensa e com menor intervalo entre eles, sendo o hormônio limitante para o desencadeamento da puberdade em fêmeas bovinas (KINDER et al., 1994).

$\mathrm{Na}$ literatura, encontram-se ganhos de peso, durante os períodos reprodutivos, muito variáveis devido às condições de meio. No entanto, existe concordância que, independente do ganho, o peso no início do período reprodutivo é fundamental em sistemas de pecuária de corte intensiva (ROVIRA, 1996; VAZ et al., 2012).

O estudo realizado em retrospectiva, de acordo com a manifestação de estros das novilhas, independente dos ganhos de pesos pré e pósdesmame, comparando novilhas cíclicas e não cíclicas, durante o período reprodutivo aos 14 meses de idades, mostra diferença $(\mathrm{P}<0,01)$ nos pesos e ganhos de peso corporal médio diário pré-desmame das novilhas cíclicas em comparação as não cíclicas, com exceções do ganho de peso pós-desmame $(\mathrm{P}<0,0554)$ e o ganho de peso corporal durante o período reprodutivo ( $\mathrm{P}>0,05$; Tabela 5$)$.

Desde a idade do desmame das novilhas ocorreram diferenças no peso corporal, nas taxas de ganhos de peso corporal médio diário e de escores corporais finais entre novilhas que viriam a ciclar ou não. Resultados semelhantes foram encontrados por ROCHA \& LOBATO (2002) e VAZ et al., (2012), que observaram que as novilhas que não conceberam foram desde o desmame até o final do acasalamento significativamente $(\mathrm{P}<0,05)$ mais leves.

As diferenças de peso médio corporal no início e final do período de acasalamento foram de 32,2 e 35,5 kg pró-novilhas cíclicas, correspondendo esse valor a 12,70 e $11,83 \%$ a mais em peso vivo, respectivamente. Em situações de propriedades, bezerras e novilhas com menores pesos corporais no desmame podem receber um tratamento diferenciado 
(PEREIRA NETO \& LOBATO, 1998), mais precoces.

possibilitando melhores condições de Houve diferença no ganho de peso realizado desenvolvimento e, consequentemente, maior pelas novilhas no período pré-desmame $(\mathrm{P}<0,01)$, probabilidade de prenhez, bem como maior número não ocorrendo o mesmo no período pós-desmame e de fêmeas em condições de acasalamento em idades durante o período reprodutivo $(\mathrm{P}>0,05)$.

Tabela 5 - Médias e erros padrão de peso, condição corporal, ganho de peso e idade de novilhas cíclicas e acíclicas no acasalamento aos 14 meses de idade

\begin{tabular}{lccc}
\hline & Cíclicas & Acíclicas & Valor de P \\
\hline Pesos, kg & & & \\
Peso ao nascimento & $31,6 \pm 0,8$ & $30,2 \pm 1,2$ & 0,3600 \\
Pesos ao desmame & $152,9 \pm 4,0$ & $124,8 \pm 6,1$ & 0,0003 \\
Início do período reprodutivo & $286,2 \pm 4,4$ & $254,0 \pm 6,8$ & 0,0002 \\
Final do período reprodutivo & $335,5 \pm 5,3$ & $300,0 \pm 8,4$ & 0,0060 \\
\hline Condição corporal período reprodutivo \# & $3,41 \pm 0,04$ & $3,18 \pm 0,07$ & 0,0049 \\
\hline GMD, kg/d & & & \\
Período pré-desmame & $0,578 \pm 0,018$ & $0,451 \pm 0,028$ & 0,0003 \\
Período pós-desmame & $0,740 \pm 0,022$ & $0,715 \pm 0,034$ & 0,0554 \\
Período reprodutivo & $0,548 \pm 0,038$ & $0,514 \pm 0,058$ & 0,6415 \\
\hline Idade acasalamento, dias & $418 \pm 3,3$ & $400 \pm 4,2$ & 0,0025 \\
\hline
\end{tabular}

\# 1- muito magra, 2 - magra, 3- média, 4 - gorda e 5 - muito gorda.

ROCHA \& LOBATO (2002) também observaram ganhos de peso corporal superiores desde o nascimento ao desmame das bezerras, porém, a partir dessa data até o final do período reprodutivo, as novilhas que conceberam mantiveram ganhos de peso corporal semelhantes ao das novilhas que não conceberam, embora as primeiras tenham sido superiores em peso corporal em todas as idades avaliadas desde o nascimento até o final do período reprodutivo.

$\mathrm{O}$ desenvolvimento pré-acasalamento torna-se importante à medida que se reduz a idade do primeiro período reprodutivo. Para tanto, tornam-se importantes os ganhos de peso corporal pré-desmame (PATTERSON et al., 1992) e pósdesmame (ROCHA \& LOBATO, 2002), sendo que planos de nutrição baixa retardam a puberdade de novilhas, podendo ser característica de seleção dentro dos rebanhos (CARVALHEIRO et al., 2006), não sendo o acasalamento aos 14 meses generalizado para todas as novilhas de reposição do rebanho.

Em rebanhos comerciais, a uniformidade da produção pode significar a diferença no resultado econômico final (FRIES et al., 2002). A eliminação das novilhas que não conceberam por uma menor precocidade sexual e possivelmente menor eficiência produtiva futura (MORRIS, 1980) é fator de aumento nas taxas de desfrute dos rebanhos (BERETTA et al., 2002).

Estudos demonstram que as novilhas estão aptas à reprodução em diferentes idades, sendo as mais tardias ao primeiro parto consequentes de baixa herança genética para puberdade precoce (LOBATO \& MAGALHÃES, 2001), fator determinante de eliminação em rebanhos com seleção para precocidade.

A diferença $(\mathrm{P}>0,05)$ na idade ao início do acasalamento das novilhas diagnosticadas cíclicas em comparação as acíclicas (418 vs 400 dias, respectivamente) foi fator determinante para $o$ melhor desempenho reprodutivo das mesmas. Melhores desempenhos reprodutivos são relatados com novilhas mais velhas ao início do período reprodutivo (ROCHA \& LOBATO, 2002).

Classificadas conforme faixas de pesos, independente dos ganhos de peso corporal pré e pós-desmame, quanto maior o peso vivo, maior foi a prenhez obtida (Tabela 6), confirmando a influência do peso corporal de novilhas ao início do período de acasalamento no índice de manifestação de estros e de prenhez.

Novilhas pesando $316 \mathrm{~kg}$ ou mais, correspondendo a $70 \%$ do peso adulto do rebanho em estudo, obtiveram $100 \%$ de manifestação de estro e $93,8 \%$ de prenhez; portanto, em sistemas de produção similares aos desenvolvidos no presente estudo, para se atingir elevado índice de 
reprodução, recomendam-se níveis nutricionais em que as novilhas possam obter ganhos de peso altos para chegarem ao início do período reprodutivo com peso corporal adequado.

Tabela 6 - Efeito do peso ao início do período reprodutivo aos 14 meses de idade sobre a manifestação de estros e de prenhez de novilhas

\begin{tabular}{lcc}
\hline & Peso ao início do período reprodutivo \\
\hline Faixas pesos, kg & Estro, \% & Prenhez, \% \\
\hline$\geq 316$ & $100,0^{\mathrm{a}}$ & $93,8^{\mathrm{a}}$ \\
$280-315$ & $83,3^{\mathrm{ab}}$ & $72,2^{\mathrm{b}}$ \\
$245-279$ & $75,0^{\mathrm{b}}$ & $68,8^{\mathrm{b}}$ \\
$\leq 244$ & $43,8^{\mathrm{c}}$ & $43,8^{\mathrm{c}}$ \\
\hline
\end{tabular}

${ }^{\mathrm{a}, \mathrm{b}, \mathrm{c}}$ Médias na coluna seguidas de letras diferentes diferem $(\mathrm{P}<0,05)$ pelo teste qui-quadrado.

ROVIRA (1996) identificou respostas crescentes em fertilidade até os $300 \mathrm{~kg}$ de peso vivo em novilhas de raças britânicas ou suas cruzas, acasaladas aos 14 meses de idade. Em estudo de probabilidade de prenhez para novilhas acasaladas entre 14 e 15 meses, BITTENCOURT et al. (2005) verificaram o peso ótimo de $338,8 \mathrm{~kg}$. Os resultados indicaram que $73,6 \%$ das variações na probabilidade de prenhez puderam ser explicadas pela variável peso ao início do acasalamento.

\section{CONCLUSÕES}

Ganhos de peso corporal elevados nos períodos pré e pós-desmame melhoram o desempenho reprodutivo de novilhas mestiças Charolês, aumentando o percentual de concepção no início do período reprodutivo. Novilhas com diagnóstico de prenhez positivo aos 14/16 meses de idade são mais pesadas, mais velhas e com melhores ganhos e escores de condição e de peso do nascimento até o final do acasalamento do que as diagnosticadas como não prenhes. A prenhez de novilhas mestiças Charolês aumenta linearmente à medida que aumenta o seu peso no início do primeiro período reprodutivo.

\section{REFERÊNCIAS}

BERETTA,V.; LOBATO, J.F.P.; MIELITZ NETTO, C.G.A. Produtividade e eficiência biológica de sistemas de produção de gado de corte de ciclo completo no Rio Grande do Sul. Revista Brasileira de Zootecnia, v.31, n.2 (suplemento), p.991-1001, 2002.

BITTENCOURT, H.R.; GOTTSCHALL, C.S.; SANT'ANA, M.F. Um modelo alternativo para a predição da probabilidade de prenhez em função do peso ao início do acasalamento. Arquivos de Ciências Veterinárias e Zoologia, v.8, n.2, p.99-104, 2005.
BYERLEY, D.J.; STAIGMILLER, R.B.; BERARDINELLI, J.G.; SHORT, R.E. Pregnancy rates of beef heifers bred either on puberal or third estrus. Journal of Animal Science, v.65, n.5, p.645-650, 1987.

CARVALHEIRO, R.; PIMENTEL, E. C. G.; CARDOSO, V.; QUEIROZ, S. A.; FRIES, L.A. Genetic effects on preweaning weight gain of Nelore-Hereford calves according to different models and estimation methods. Journal Animal Science, v.84, n.1, p.2925-2933. 2006.

FRIES, L.A.; SCHENKEL, F.S.; ALBUQUERQUE, L.G. Efeitos da Heterogeneidade de Variância Residual entre Grupos de Contemporâneos na Avaliação Genética de Bovinos de Corte. Revista Brasileira de Zootecnia, v.31, n.4, p.1680-1688, 2002.

GREGORY, K.E.; LUNSTRA, D.D.; CUNDIFF, L.V. $\mathrm{KOCH}$, R.M. Breed effects and heterosis in advanced generations of composite populations for puberty and scrotal traits of beef cattle. Journal Animal Science, v.69, n.7, p.2795-2807, 1991.

KINDER, J.E.; ROBERSON, M.S.; WOLFE, M.W. STUMPF, T.T. Management factors affecting puberty in the heifer. In: FIELDS, M.J. \& SAND, R.S. (eds.). Factors affecting calf crop. Boca Raton: CRC Press, 1994. Capítulo 5, p. 69-89.

LOBATO, J.F.P.; MAGALHÃES, F.R. Comportamento reprodutivo de vacas primíparas aos 24 e 36 meses de idade. Arquivos da Faculdade de Veterinária UFRGS. v.29, n.2, p.139-146, 2001.

LOWMAN, B.G.; SCOTT, N.; SOMERVILLE, S. Condition scoring beef cattle. Edinburgh: East of Scotland College of Agriculture. 1973. 8p.

MORENO, J.A. Clima do Rio Grande do Sul. Porto Alegre. Secretaria da Agricultura. 1961.41p.

MORRIS, C.A. A review of relationships between aspects of reproduction in beef heifers and their lifetime production. I - Associations with age at first joining. Animal Breeding Abstracts, n.48, p.655-676,1980.

NATIONAL RESEARCH COUNCIL - NRC Nutrient 
requeriment of beef cattle. Washington D.C.: National Academy Press, 1996.

OSORO, K.O. Effecto de las principales variables de manejo sobre los parametros reproductivos en las vacas de cria. Producción y Sanidade Animales, v.1, n 1-2, separata. n.7, p. 87-111, 1986.

PATTERSON, D.J.; PERRY, R.C.; KIRACOFE, G.H.; BELLOWS, R.A.; STAIGMILLER, R.B.; CORAH, L.R. Management considerations in heifers development and puberty. Journal Animal Science, v.70, n.12, p.40184035, 1992.

PEREIRA NETO, O.A.; LOBATO, J.F.P.; Efeitos da ordem de utilização de pastagens nativas melhorada no desenvolvimento e comportamento reprodutivo de novilhas de corte. Revista Brasileira de Zootecnia. v.27, n.1, p.60-65, 1998.

PILAU,A.; LOBATO, J.F.P.; Recria de bezerras com suplementação no outono e pastagem cultivada no inverno. Revista Brasileira de Zootecnia, v.35, n.6. p.2388-2396, 2006.

RESTLE, J.; POLLI, V.A.; SENNA, D.B. Efeito de grupo genético e heterose sobre a idade e peso a puberdade e sobre o desempenho reprodutivo de novilhas de corte. Pesquisa Agropecuária Brasileira, v.34, n.4, p.701-707, 1999.

ROCHA, M.G.da; LOBATO, J.F.P. Avaliação do desempenho reprodutivo de novilhas de corte primíparas aos dois de idade. Revista Brasileira de Zootecnia, v.31, n.3 (supl.), p.1388-1395, 2002.

ROVIRA, J. Manejo nutritivo de los rodeos de cria en pastoreo. Montividéo. Hemisfério Sur. 1996. 287 p.
SCHILLO, K.K. Effects of dietary energy on control of luteinizing hormone secretion in cattle and sheep. Journal of Animal Science, v.70, n.12, p.1271-1282, 1992.

SEMMELMANN, C.E.N.; LOBATO, J.F.P.; ROCHA, M.G. Efeito de sistemas de alimentação no ganho de peso e desempenho reprodutivo de novilhas nelore acasaladas aos 17/18 meses. Revista Brasileira de Zootecnia, v.30, n.3 (supl.), p.835-843, 2001.

VALLE, E.R.do; ANDREOTTI, R.; THIAO, L.R.L. Estratégias para aumento da eficiência reprodutiva e produtiva em bovinos de corte. Campo Grande: EMBRAPA-CNPGC. 1998. 80 p. (Documentos, 71).

VAZ, R.Z.; LOBATO, J.F.P.; RESTLE, J. Influence of weaning age on the reproductive efficiency of primiparous cows. Revista Brasileira de Zootecnia. v.39, n.2, p.299307, 2010.

VAZ, R.Z.; RESTLE, J.; VAZ, M.B.; PASCOAL, L.L.; VAZ, F.N.; BRONDANI, I.L.; ALVES FILHO, D.C.; NEIVA, J.N.M. Desempenho de novilhas de corte até o parto recebendo diferentes níveis de suplementação durante o primeiro período reprodutivo aos 14 meses de idade. Revista Brasileira de Zootecnia. v.41, n.3, p. 797 806, 2012.

WILLIAMS, C.B.; JENKINS, T.G. A computer model to predict composition of empty body weight changes in cattle at all stages of maturity. Journal Animal Science, v.76, n.4, p.980-987, 1998.

WILTBANK, J.N.; ROBERTS, J.N.; ROWDEN, L. Reproductive performance and profitability of heifers feed to weight 272 or $318 \mathrm{~kg}$ at the start of the first breeding season. Journal of Animal Science, v.60, n.1, p.25-35, 1985. 